OPEN ACCESS

Edited by:

Sagar K. Thakkar,

Nestlé Research Center, Singapore

Reviewed by:

Stephan Van Vliet,

Duke University, United States

Patrik Hansson,

UiT the Arctic University of

Norway, Norway

Claire Gaudichon,

AgroParisTech Institut des Sciences et Industries du Vivant et de

L'environnement, France

*Correspondence:

Amber M. Milan

a.milan@auckland.ac.nz

Specialty section:

This article was submitted to Nutrition and Metabolism,

a section of the journal

Frontiers in Nutrition

Received: 17 December 2020 Accepted: 30 March 2021 Published: 30 April 2021

Citation:

Fatih M, Barnett MPG, Gillies NA and Milan AM (2021) Heat Treatment of Milk: A Rapid Review of the Impacts

on Postprandial Protein and Lipid Kinetics in Human Adults.

Front. Nutr. 8:643350.

doi: 10.3389/fnut.2021.643350

\section{Heat Treatment of Milk: A Rapid Review of the Impacts on Postprandial Protein and Lipid Kinetics in Human Adults}

\author{
Mona Fatih ${ }^{1}$, Matthew P. G. Barnett ${ }^{2,3}$, Nicola A. Gillies ${ }^{2,4}$ and Amber M. Milan ${ }^{2,4 *}$ \\ ${ }^{1}$ Polytech School of Engineering, University of Angers, Angers, France, ${ }^{2}$ AgResearch Ltd., Grasslands Research Centre, \\ Palmerston North, New Zealand, ${ }^{3}$ Riddet Institute, Hosted by Massey University, Palmerston North, New Zealand, ${ }^{4}$ The \\ Liggins Institute, The University of Auckland, Auckland, New Zealand
}

Background: Most milk consumed by humans undergoes heat treatment to ensure microbiological safety and extend shelf life. Although heat treatment impacts the structure and physiochemical properties of milk, effects on nutrient absorption in humans are unclear. Therefore, a rapid review was performed to identify studies conducted on healthy human adult subjects that have assessed the impacts of heat treatment of milk on protein and fat digestion and metabolism in the postprandial period (up to $24 \mathrm{~h}$ ).

Methods: Relevant databases (Medline, EMBASE, Cochrane, Scopus) were systematically screened for intervention studies on healthy adult men and women that assessed the impact of consuming heat-treated milk on the postprandial kinetics or appearance in peripheral circulation or urine of ingested proteins and/or lipids. The risk-of-bias assessment tool 2 was used for quality assessment.

Results: Of 511 unique database records, 4 studies were included encompassing 6 study treatments ( $n=57$ participants, 20-68 years). Three studies evaluated pasteurization, two evaluated ultra-high temperature (UHT) treatment, and one evaluated oven-heated milk. Protein and lipid appearances in peripheral blood were reported in two sets of two studies. None of the studies used the same heat treatments and outcome measures, limiting generalization of effects. Protein appearance $(\mathrm{ng} / \mathrm{mL}$ or area under the curve) (as plasma amino acids - lysine) was reduced when milk was oven-heated for $5 \mathrm{~h}$ in one study ( $n=7$ participants), while the other study reported a reduced retention of dietary N with UHT milk ( $n=25$ participants). Overall plasma triacylglycerol responses were unaffected by milk heat treatments reported, but plasma fatty acid composition differed. The studies observed higher plasma myristic and palmitic acid abundance with successive heat treatment at $2 \mathrm{~h}$ ( $n=11$ participants; pasteurized) and 4h ( $n=14$ participants; UHT) after ingestion; other differences were inconsistent. All studies had moderate-high risk of bias, which should be taken into consideration when interpreting findings.

Discussion: This review identified few studies reporting the effects of milk heat treatment on postprandial nutrient responses in adults. Although the findings suggest that milk 
heat treatment likely affects postprandial protein and lipid dynamics, generalization of the findings is limited as treatments, outcomes, and methods differed across studies. Because of the study variability, and the acute post-prandial nature of the studies, it is also difficult to draw conclusions regarding potential long-term health outcomes. However, the possibility that altered digestive kinetics may influence postprandial protein retention and anabolic use of dietary $\mathrm{N}$ suggests heat treatment of milk may impact outcomes such as long-term maintenance of muscle mass.

Keywords: lipid, protein, postprandial, dairy, pasteurized, ultra-high temperature

\section{INTRODUCTION}

Heat treatment is a widely used technique in the dairy industry, as fresh liquid milk is a product with a short shelf-life. In addition, although the careful use of animal husbandry and onfarm hygiene practices enables raw milk of high microbiological quality to be obtained, raw milk can be microbiologically unsafe for human consumption $(1,2)$, due to the presence of harmful bacteria including Campylobacter, Salmonella, Shiga toxin-producing Escherichia coli (3) and Listeria monocytogenes $(1,2)$. Heat treatment has been defined as follows by the International Dairy Federation: "Any intentional heating above $50{ }^{\circ} \mathrm{C}$ for a sufficient time such that there is a reduction in the concentration of one or more microorganisms is considered heat treatment" (4). Standard heat treatment includes hightemperature short time pasteurization $\left(72\right.$ to $80^{\circ} \mathrm{C}$ for 15 to $30 \mathrm{~s}$ ) and ultra-high temperature (UHT) processing $\left(135\right.$ to $150^{\circ} \mathrm{C}$ for 1 to $10 \mathrm{~s}$ ) (4), with the primary objective to make milk safe for human consumption.

With a view to understanding the impact of milk processing on human health, investigations of the consequences of processing on milk structure and physical properties have been conducted using in vitro systems (5-7). Pasteurization and UHT processing were shown to increase the aggregation of fat and protein into a semisolid curd under simulated gastric conditions (5). UHT milk was shown to have faster rates of protein hydrolysis compared to pasteurized milk and a faster release of fat globules during digestion. Those results were explained by differences in the structure of the different milk curds (6). Protein modifications occurring during heating processes (i.e., pasteurization) have been shown to impact protein composition and function of the milk fat globule membrane, which have the potential to impact digestion (8). Those structural changes, especially in UHT milk, include a looser curd structure, creating a larger surface area for the diffusion of pepsin into the curd (7). A smaller weight of milk curd can lead to a quicker protein hydrolysis and thus, speed up the gastric emptying process (6). Moreover, a rodent study assessing the impact of different thermal treatments (UHT, pasteurized, and spray-dried milks) on the bioavailability of dairy proteins showed a modification of the postprandial splanchnic protein extraction and a small but significant impairment in digestibility following spray-dried milk, with no impact of heat treatment on nitrogen availability. The authors concluded that altered postprandial metabolism may relate to the degree of protein lactosylation (9); lactosylation is enhanced by heat treatment (10).

However, the impact of heat treatment on the ways in which proteins and lipids are absorbed in humans have not been detailed by these in vitro or animal studies. Our objective was to identify studies conducted on healthy human adult subjects that have assessed the impacts of heat treatment of milk on protein and fat digestion in the postprandial period (up to $24 \mathrm{~h}$ ), using non heat-treated milk as a comparison across studies where possible. For this purpose, we used a rapid review methodology to review the literature.

\section{METHODS}

A rapid review methodology was used to complete this study. The objective of a rapid review is to synthesize knowledge in order to produce information under time constraints by simplifying the systematic review process. Systematic reviews usually take many months, or even up to years to produce, whereas rapid reviews typically only take from 1-6 months, and may limit the scope of sources searched (e.g., gray literature) $(11,12)$.

Using the Population Intervention Comparator Outcome Time (PICOT) format (13), our research question was formulated as follows: Are there differences in protein and/or lipid digestion and metabolism in the $24 \mathrm{~h}$ following consumption of different types of heat-treated milk, or heat-treated compared to non-heat-treated milk, among adult men and women (18-70 years)? (Table 1).

TABLE 1 | PICOT criteria employed to define the research question.

\begin{tabular}{ll}
\hline Criteria & Description \\
\hline $\begin{array}{l}\text { Participants } \\
\text { Intervention }\end{array}$ & $\begin{array}{l}\text { Human men and women (18-70 years) } \\
\text { Comparison group }\end{array}$ \\
$\begin{array}{l}\text { Non-heated milk } \\
\text { heat treatment }\end{array}$ \\
$\begin{array}{l}\text { Outcome of } \\
\text { interest }\end{array}$ & metabolism \\
Time & $\leq 24 \mathrm{~h}$ following ingestion of milk
\end{tabular}


TABLE 2 | Inclusion and exclusion criteria applied in article screening.

\begin{tabular}{|c|c|c|}
\hline & Inclusion & Exclusion \\
\hline Population & $\begin{array}{l}\text { Healthy human participants } \\
\text { Men and women } \\
\text { Adults (18-70 years) }\end{array}$ & $\begin{array}{l}\text { Animals } \\
\text { Population with chronic } \\
\text { diseases (e.g., cardiovascular } \\
\text { diseases, cancer) metabolism } \\
\text { disorders (e.g., thyroid) or } \\
\text { gastrointestinal diseases (e.g., } \\
\text { celiac disease, inflammatory } \\
\text { bowel disease) } \\
\text { Populations with known } \\
\text { intolerance to milk }\end{array}$ \\
\hline Study design & $\begin{array}{l}\text { Interventional } \\
\text { Follow up maximum } 24 \text { h }\end{array}$ & $\begin{array}{l}\text { Observational } \\
\text { Study cases } \\
\text { Interventions over } 24 \mathrm{~h} \text { long }\end{array}$ \\
\hline Study setting & Clinical trial & Community \\
\hline Intervention & $\begin{array}{l}\text { Consumption of a meal with } \\
\text { milk that was heat treated } \\
\text { (e.g. UHT, pasteurization, } \\
\text { ESL) }\end{array}$ & $\begin{array}{l}\text { If milk was not heat treated and } \\
\text { only went through another type } \\
\text { of process (e.g., microfiltration, } \\
\text { homogenization) }\end{array}$ \\
\hline Outcome & $\begin{array}{l}\text { protein and/or lipid kinetics; } \\
\text { protein and/or lipid } \\
\text { appearance and clearance } \\
\text { in blood circulation and/or } \\
\text { urine }\end{array}$ & \\
\hline Publication status & & $\begin{array}{l}\text { Full text is not available in } \\
\text { English }\end{array}$ \\
\hline
\end{tabular}

According to the International Dairy Federation, "Any intentional heating above $50^{\circ}$ C for a sufficient time such that there is a reduction in the concentration of one or more microorganisms is considered heat treatment" (4). ESL, extended shelf life; UHT, ultra-high temperature.

\section{Inclusion Criteria}

The inclusion criteria (Table 2) were determined by one reviewer $(M F)$ and then shared for approval with the second reviewer (AM).

\section{Search Strategy}

The electronic databases Medline (ovid), EMBASE (ovid/ 1980present), The Cochrane Library and Scopus were searched without any restrictions to the time of publication. The search was carried out from June 10-16th 2020. The research question was separated in four concepts grouping all the Medical Subject Headings (MeSH) and keywords relevant to each concept. All those terms were linked within each concept with the connector $\mathrm{OR}$ and the four concepts were joined using the connector AND. The MeSH terms were adapted according to the specificity of each database. No MeSH terms were used to search Scopus but only the keywords in the title, abstract and keywords of the database. The full search strategy and its adaptation for each database can be found in Supplemental Tables 1-4.

All the search results were exported to the reference manager Mendeley (v1.19.4 Elsevier Inc., Amsterdam, Netherlands) where duplicate articles were removed.

\section{Screening Process}

Titles and abstracts of articles were screened independently by two reviewers (MF and AM) against the inclusion and exclusion criteria. The discrepancies were resolved through discussion, or by consultation with a third reviewer if necessary (NG). If the decision to include an article was unclear at any stage, then the full text was obtained. Next, the full text of relevant articles was obtained and screened to ensure their eligibility.

\section{Data Extraction}

The two reviewers independently extracted the following information from the relevant full-text articles: author, date and country of the article, purpose of the study, type of heat treatment, temperature and length of the treatment, milk of comparison, volume of milk, time of follow-up, number, sex and age range of the participants, outcome measurement and results.

\section{Quality Assessment}

The risk of bias was assessed using the Cochrane risk-of-bias assessment tool for randomized trials (RoB 2) (14). The risk of bias was assessed (by MF) for each independent outcome within a study where differences between the outcomes were observed (e.g., missing data for a specific outcome, different number of analyzed samples).

\section{RESULTS}

\section{Study Selection}

A total of 1,076 articles were identified from the four database searches and exported to Mendeley. The duplicate check was then completed, resulting in 511 articles. After the title and abstract screening, 506 articles did not match the inclusion criteria and were excluded from full-text review. Finally, we assessed the full-text of 5 articles, from which 1 was excluded because the measured outcomes did not meet the inclusion criteria (Figure 1).

\section{Study Characteristics}

Two of the studies were conducted in Finland by the same group $(15,16)$. One was conducted in France $(17)$, and one in Sweden (18). One study was a randomized parallel trial (17) and the other three studies were randomized cross-over trials $(15,16,18)$. In total, $n=57$ subjects were included. All studies were conducted on both male and female subjects. Most subjects were aged from 20 to 40 years old but one study reported their eldest subject to be 68 (15). All the subjects were reportedly healthy. In two of the studies $(15,16)$, subjects reported gastrointestinal (GI) symptoms after drinking milk but no lactose intolerance had been previously diagnosed. Across the four studies, there were six treatment groups in which heat-treated milks were consumed. Three studies measured the effects of pasteurization (15-17), two measured the effects of UHT treatment $(16,17)$ and in one study the milk was heated in an oven (18). Measured outcomes were glycemia in three of the studies (15-17), insulinemia, lipemia, inflammation and GI symptoms in two of the studies $(15,16)$, amino acids (AAs) in plasma in one study (18) and AAs, protein and urea in serum, urinary creatinine, urinary urea and dietary $\mathrm{N}$ incorporation in one study (17) (Table 3). 


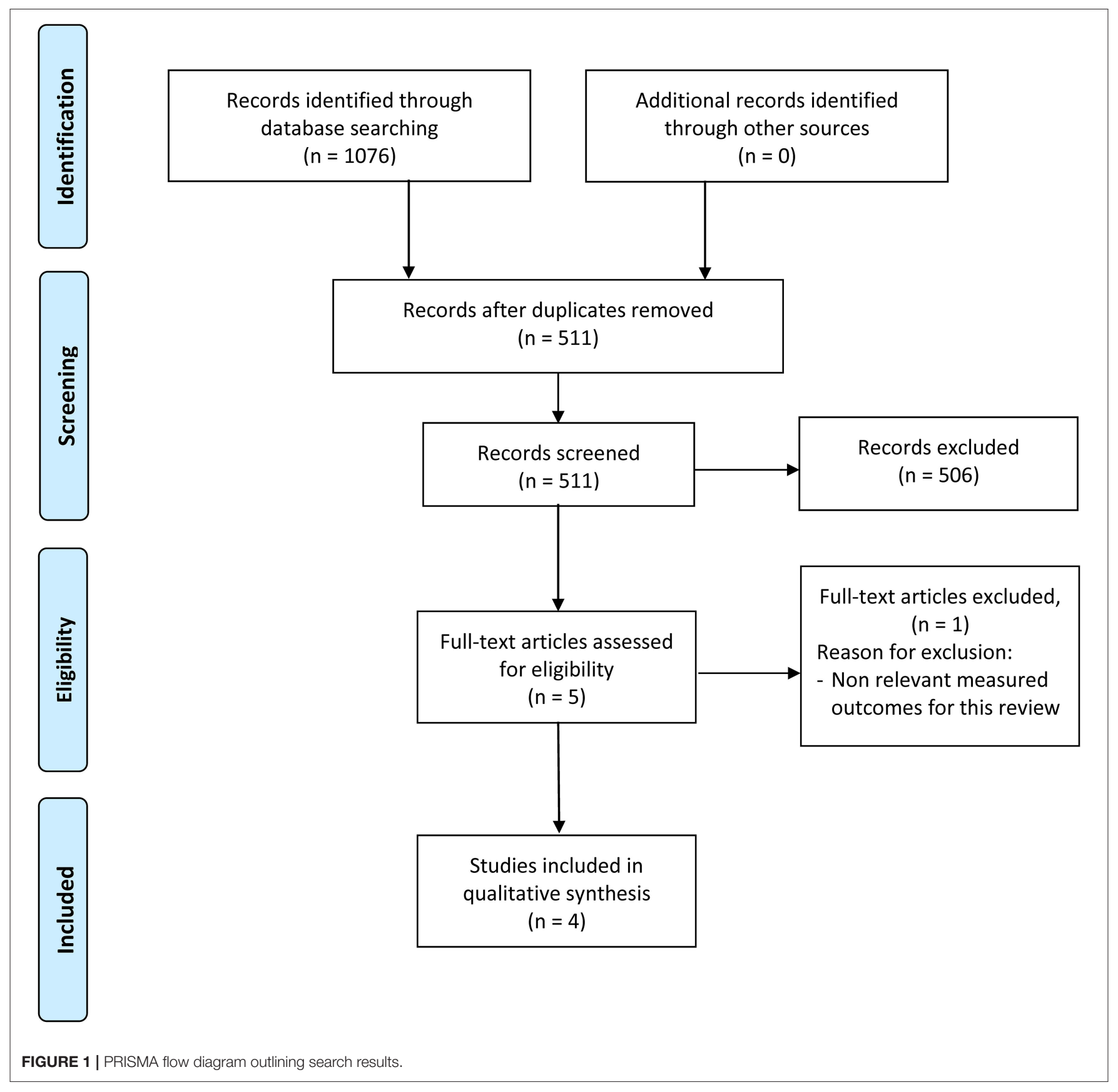

\section{Risk of Bias Within Studies}

Three of the studies were assessed with some concerns on the overall bias (15-17) and one was assessed with a high risk of bias (18).

These findings reflected a lack of reporting within the methods used in the study by the investigator team (e.g., lack of reporting of a randomization strategy or a pre-specified analysis plan before having the results). For instance, pre-specified analysis plans were not specified or available for all studies, meaning that none of the included studies could satisfy a low risk of bias under Domain 5 of the tool. No differences in risk assessment were found within studies reporting multiple outcomes, so risk of bias has been presented only once per study (Figure 2).

\section{Summary of Study Findings}

\section{Proteins and Amino Acids}

The study that measured the plasma AA response $2 \mathrm{~h}$ after ingestion of milk heated in the oven [Ljungqvist et al. (18)] found a significant drop in the lysine plasma concentration between the milks heated for $0 \mathrm{~h}(-3.9 \%)$ and $5 \mathrm{~h}(-10.1 \%)$; hence, compared to raw milk $(0 \mathrm{~h})$ the lysine plasma concentration was lower. However, the study by Lacroix et al. that assessed the plasma AA 


\begin{tabular}{|c|c|c|c|c|}
\hline & $\begin{array}{l}\text { Lacroix et } \\
\text { al. } 2008\end{array}$ & $\begin{array}{l}\text { Ljungqvist } \\
\text { et al. } 1979\end{array}$ & $\begin{array}{l}\text { Nuora et } \\
\text { al. } 2018 \mathrm{a}\end{array}$ & $\begin{array}{l}\text { Nuora et } \\
\text { al. } 2018 b\end{array}$ \\
\hline \multicolumn{5}{|l|}{ Domain 1: Risk of bias arising from the randomization process } \\
\hline \multicolumn{5}{|c|}{ Domain 2: risk of bias due to deviations from the intended interventions } \\
\hline \multicolumn{5}{|l|}{ Domain 3: Missing outcome data } \\
\hline \multicolumn{5}{|l|}{ Domain 4: Risk of bias in measurement of the outcomes } \\
\hline \multicolumn{5}{|l|}{ Domain 5: Risk of bias in selection of the reported result } \\
\hline Overall risk of bias & & & & \\
\hline
\end{tabular}

FIGURE 2 | Quality assessment of studies using the Risk of Bias 2 tool. Green indicates low risk, yellow indicates some concerns, red indicates high risk.

concentrations after the ingestion of micro filtered milk (MF), pasteurized milk (PM) and UHT-treated milk (17) did not report any significant differences across plasma AA, including lysine plasma concentration. Lacroix et al. also reported significant differences between the time courses of dietary $\mathrm{N}$ transfer into serum $\mathrm{AA}$, urea $\mathrm{N}$, and protein pools, using ${ }^{15} \mathrm{~N}$ milk labeling. UHT showed $5 \%$ higher dietary $\mathrm{N}$ in the body urea pool after $8 \mathrm{~h}$ than $\mathrm{MF}$ and $\mathrm{PM}$; in serum proteins this elevation was $\sim 1 \%$ higher. A significant meal effect was observed after the consumption of UHT milk compared to PM and MF milk (Table 4). A postprandial reduction in dietary $\mathrm{N}$ retention of $8 \%$ was also observed after ingestion of the UHT compared to the two other types of milk (Table 4).

\section{Lipids}

No significant differences were found in the plasma triacylglycerol concentrations between homogenized, pasteurized and UHT milk (16), nor in the blood triacylglycerol concentrations between raw milk ("native milk"; NM) and homogenized and pasteurized milk (HPM) (15). However, significant differences were found in the fatty acid composition of plasma lipids. Myristic, palmitic, and stearic acids were found to be higher $4 \mathrm{~h}$ after the consumption of the HPM compared to the NM. However, no significant differences were observed at the $2 \mathrm{~h}$ time point (15). In the other study measuring this outcome (16), significant differences were also reported. At the $2 \mathrm{~h}$ time point, myristic, palmitic, oleic and linoleic acids were found to be significatively higher after the UHT milk and the PM compared to the HPM. At the $4 \mathrm{~h}$ time point, linoleic acids levels were found to be higher after PM compared to the UHT milk that was itself higher than the HPM.

\section{Plasma Glucose and Insulinemia}

The three papers that measured plasma glucose concentration after drinking the milks did not report any significant differences between milks processed by different methods regarding that outcome (15-17). No significant differences were reported for plasma insulin levels either $(15,16)$.

\section{DISCUSSION}

The purpose of this review was to identify studies that assessed the impact of heat treatment of liquid milk on protein and lipid digestion and metabolism in human adults. A total of four papers reporting studies on healthy human subjects were included, of the 511 initially identified. All studies were assessed as having moderate-high risk of bias. Two of the studies reported outcomes related to lipids $(15,16)$ and the other two reported outcomes related to proteins $(17,18)$. Despite the topic of milk heat treatment being relevant for commercial milk products (3) and consumer nutritional preferences $(19,20)$, we did not find many studies measuring our outcomes of interest (i.e., protein and fat metabolism after consumption) directly in human subjects.

Our search resulted in 511 articles to screen, although only four articles met the inclusion criteria, all of which described studies that were conducted in Europe. Most were excluded for reasons such as being conducted on animals $(9,21,22)$ or infants (23-25), only assessing physical and technological milk properties (26) (e.g., rheological and thermal properties, microstructure), participants drinking milk protein mix (e.g., whey beverages) but not plain milk $(27,28)$, studies based on plant-based milk $(29,30)$, or measured outcomes which were not relevant for this review (e.g., vitamins, iron, zinc) (31). Indeed, a recent systematic review of the processing impacts on milk protein digestion (32) identified only two human studies meeting their criteria, of which only one [Lacroix et al. (17)] investigated liquid milk (in this case, defatted) and is therefore common to our comparison. The large number of irrelevant articles may have been avoided with refinement of search terms; however, the current search strategy also highlighted areas which may be suitable for future reviews into the effects of heat treatment of milk on digestion in contexts other than liquid milk or human populations. As only four studies were included in the final assessment, this suggests either a lack of studies conducted specifically on adult human subjects for the specified outcomes or a lack of additional search terms that could be relevant. For instance, terms such as in vivo, nitrogen metabolism, or alternate terminology for heat treatments may have been missed, in addition to possible content available in the gray literature.

Half of the studies were conducted on self-described milk intolerant people but with no clinically diagnosed intolerance 
TABLE 3 | Characteristics of included studies assessing postprandial protein or lipid responses to heat treated milk in adults.

Comparison milk

Intervention

Study protocol prior to testing

Test meal

Volume of milk consumed

Duration of follow-up

Frequency of sampling

Milk characteristics
Fat content - test

Fat content - control

Protein content - test

Protein content - contro
Lacroix et al. (2018) (17)

France
To assess impact of heat treatment
(microfiltration, Pasteurization, UHT) on protein quality (measured by nitrogen metabolism) following

single meal

25 (11M; 14F)

$44 \%$

Age range not reported, range of means: $23.5 \pm 6.9-27.1 \pm 7.8$

1. Pasteurized 2. UHT

Pasteurization: $72^{\circ} \mathrm{C}$; UHT: $140^{\circ} \mathrm{C}$

Pasteurization: 20 s; UHT: 5 s

Microfiltered

Standardized diet, adjusted to participant's body weight, was provided for one-week prior to the study day. Overnight fast prior to

testing.

No test meal consumed with the milk.

$500 \mathrm{~mL}$

$8 \mathrm{~h}$

$30,60,90,120,150,180,240$ $300,360,420$, and 480 min after ingestion.

Defatted milk

Defatted milk

$23.3 \mathrm{~g}$

$23.3 \mathrm{~g}$

Ljungqvist et al. (1979) (18)

Sweden

To assess impact of lactose

hydrolysis of skim milk powder on

lysine availability (in heat treated

samples)

7 (3M; 4F)

$43 \%$

24-29

Lactose hydrolyzed freeze-dried skim milk heated in oven

$66{ }^{\circ} \mathrm{C}$

1,3 , and $5 h$

Lactose hydrolyzed freeze-dried skim milk without oven-heat treatment

Overnight fast prior to testing.$$
\text { Orig }
$$

Milk samples were mixed with gluten (1:1 on basis of protein content)

$400 \mathrm{~mL}$

$2 \mathrm{~h}$

$2 \mathrm{~h}$ after ingestion.

Not reported
Not reported
Not reported
Not reported
Nuora et al. (2018a) (15)

Finland

To assess impact of native milk v homogenized \& pasteurized milk on gastrointestinal symptoms, inflammation, transit, intestinal pressure, glycemia, insulinemia

or lipemia

11 (5M; 6F

$45 \%$

24-68

Homogenized pasteurized

$72-73^{\circ} \mathrm{C}$

$15 s$

Raw milk

Non-dairy diet for 5 days prior to the study day. Overnight fast prior to testing.

SmartBar (Given Imagine, Israel)

$400 \mathrm{~mL}$

$4 \mathrm{~h}$

$20,40,60,90,120,180$, and $240 \mathrm{~min}$ after ingestion.

Not reported

Not reported

$34.6 \pm 0.6 \mathrm{~g} / \mathrm{kg}$

$34.8 \pm 1.7 \mathrm{~g} / \mathrm{kg}$
Nuora et al. (2018b) (16)

Finland

To assess impact of milk

processing on gastrointestina symptoms, inflammation, lipemia, glycemia, insulinemia

$14(6 \mathrm{M} ; 8 \mathrm{~F})$

$43 \%$

20-45

1. Homogenized pasteurized. 2. Homogenized UHT

Homogenized Pasteurization: 73 ${ }^{\circ} \mathrm{C}$; Homogenized UHT: $135^{\circ} \mathrm{C}$ Homogenized Pasteurization: $15 \mathrm{~s}$; UHT: $3 \mathrm{~s}$

Pasteurized $^{a}$

Non-dairy diet for 5 days prior to the study day. Overnight fast prior to testing.

Rice cakes (24g), turkey cold cuts (85g), cucumber (50g)

$400 \mathrm{~mL}$

$5 \mathrm{~h}$

20, 40, 60, 90, 120, 180, 240, and $300 \mathrm{~min}$ after ingestion.

Not reported

Not reported

Not reported

Not reported

a Pasteurized milk was heated under the same conditions as the homogenized pasteurized milk, but did not undergo earlier homogenization at 16 MPa before heat treatment. F, female; UHT, ultra-high temperature. 
TABLE 4 | Findings of included studies assessing postprandial protein or lipid responses to heat treated milk in adults.

\begin{tabular}{|c|c|c|c|c|}
\hline & Lacroix et al. 2008 & Ljungqvist et al. 1979 & Nuora et al. 2018a & Nuora et al. 2018b \\
\hline $\begin{array}{l}\text { Outcome } \\
\text { measurements }\end{array}$ & $\begin{array}{l}\text { Blood glucose serum urea, AA, protein, N } \\
\text { urinary creatinine \& urea, ammonia, N N } \\
\text { incorporation into body pools }\end{array}$ & $\begin{array}{l}\text { Plasma AA\% molar ratio of } \\
\text { AA }\end{array}$ & $\begin{array}{l}\text { Gastrointestinal symptoms, } \\
\text { inflammation, transit, } \\
\text { intestinal pressure, } \\
\text { glycemia, insulinemia, } \\
\text { lipemia/fatty acids }\end{array}$ & $\begin{array}{l}\text { Gastrointestinal symptoms, } \\
\text { inflammation, lipemia, } \\
\text { glycemia, insulinemia }\end{array}$ \\
\hline Significant results & 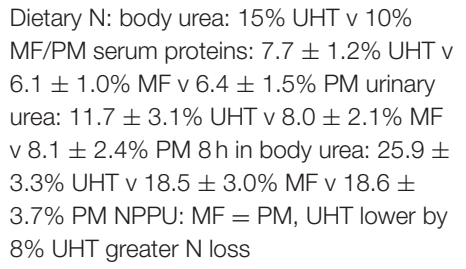 & $\begin{array}{l}\text { Limited plasma lysine \& } \\
\text { sulfur } A A \text { in all heat-treated } \\
\text { milk } v \text { unheated: lysine } \\
\text { plasma } A A \text { at }-3.9 \text { at } 0 \mathrm{~h} \\
\text { and at }-10.1 \text { at } 5 \mathrm{~h}\end{array}$ & $\begin{array}{l}\text { Higher plasma myristic, } \\
\text { palmitic, stearic acid } 4 \mathrm{~h} \\
\text { after HPM than NM }\end{array}$ & $\begin{array}{l}\text { Higher plasma myristic, } \\
\text { palmitic, oleic, linoleic } 2 \mathrm{~h} \\
\text { after UHT or PM than HPM } \\
\text { linoleic higher PM than UHT, } \\
\text { also UHT higher than HPM } \\
\text { at } 4 \mathrm{~h}\end{array}$ \\
\hline Quality assessment & Some concerns & High risk & Some concerns & Some concerns \\
\hline
\end{tabular}

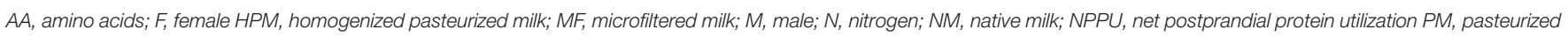
milk; UHT, ultra-high temperature.

$(15,16)$. GI symptoms were indeed described by study participants. It is unclear whether the inclusion of participants who experience symptoms such as bloating or cramping may have influenced the outcome measures of digestion, and it is not possible to compare and contrast evidence due to the small number of studies conducted. We did not take into consideration the reported outcomes of those studies regarding GI symptoms and inflammation markers as they were not outcomes of interest for this review. Although there is some evidence that plasma AA appearance after milk ingestion is unimpaired in subjects with lactose intolerance, other forms of dairy intolerance may impact plasma AA (33) or other micronutrient responses (34). Conducting studies on subjects that do not experience GI symptoms would be the next step in getting a better understanding of how heat processing influences the composition of circulating fatty acids, as both studies evaluated in this review included subjects with reported GI symptoms.

Only one study assessed outcomes related to protein metabolism (17) with this study also investigating serum AA dynamics. This showed that protein digestion may be accelerated with heat treatment, in this case UHT, with this change in digestive dynamics potentially driving enhanced anabolic use of dietary $\mathrm{N}$ specifically in serum proteins. However, this study also showed that net postprandial protein utilization (NPPU) was significantly reduced in the UHT group, indicating that more nitrogen/amino acids were oxidized in the UHT treatment. This suggests that overall protein retention was lower, and on a wholebody level the lower NPPU of the UHT treatment group reflects a reduced anabolic effect. One other study also assessed AA dynamics in plasma (18). In this case, AA concentrations at $2 \mathrm{~h}$ were lower with heat-treated milk (oven heated) vs. raw milk, suggesting reduced AA availability after heat treatment. However, it is also possible that the lower AA concentrations after heat treatment may reflect more rapid clearance from plasma and use for protein synthesis. The impacts of heat treatment on protein digestion have been assessed in vitro (6) and in animals $(9,21,35)$, and indeed, many studies that were excluded from the review assessed protein digestion yet in the context of derivatives of liquid milk (36) or in non-adult populations $(23,24)$. Yet, few studies have measured protein or amino acid dynamics in human adult subjects. Given the large body of evidence to support protein modifications to dairy products in vitro and in animal models [as reviewed by van Lieshout et al. (32)], it is perhaps surprising so few human studies exist.

The quality assessment indicated that some concerns on the risk of bias existed in three of the studies (15-17) with one study having a high risk of bias (18). The study by Ljungqvist et al. (18) was considered to have a high risk of bias primarily because the number of samples included in the results did not always match the number of participants, nor were they consistent at each time point, and no explanation was provided for this discrepancy. The study design and implementation was also unclear (e.g., no information is provided about the randomization of the sequence, if the trial is blind or double-blind) and may in part be explained by the time the study was conducted (c. 1979) relative to the introduction of standard reporting guidelines such as Consolidated Standards of Reporting Trials (CONSORT) (37). Indeed, most of the studies may have had higher quality assessment scores if the research methodology had been reported more thoroughly. In many cases, domains were scored with at least some concerns on the risk of bias because information was missing (e.g., a clear explanation on how the randomization sequence was obtained, no indication of whether the outcomes were measured on all the participants, reporting of the subject characteristics). Taking the RoB 2 tool guidelines (14) into account when determining the design of a randomized trial and then when reporting the methodology would help to avoid any doubts on the reliability of the trial's results. The quality of the three most recent papers (15-17) appears to be satisfactory in their lower risk of bias to provide a reliable quality of evidence due to their detailed reporting of the milk characteristics, inclusion and exclusion criteria, experimental design and methods of analysis of the outcomes. 
The overall findings suggest significant differences in the plasma fatty acid composition due to milk processing methods, including greater plasma concentrations of myristic and palmitic acids after UHT relative to HPM (16), and relative to NM (raw milk) (15). However, it is important to note that the two studies assessing this outcome $(15,16)$ were conducted by the same group of researchers so similarities in methodology used could contribute to the alignment of these findings. Moreover, each study made comparisons between different types of milk processing, so it is not possible to determine whether consistent results have been observed across studies for any specific milk processing type. Subjects also did not have their diet standardized, apart from not consuming dairy products 5 days before the trial. Participants of both studies also experienced GI symptoms after milk consumption such as cramping or bloating $(15,16)$. It is possible that these symptoms could influence the findings of nutrient appearance in blood circulation. There is evidence that GI symptoms $(38,39)$, as well as GI disorders including inflammatory bowel disease, Crohn's disease and celiac disease (40-42) are associated with reduced absorption of some nutrients. GI symptoms such as diarrhea or constipation are also known to be characterized by changes to GI transit times (43); however, the extent to which these symptoms impact small intestinal absorption, or whether these factors influences any of the reported findings is not clear. These studies were not able to determine the mechanisms for blood circulating fatty acid composition differences at specific time points following consumption of processed milks. It is still unclear how the lipid droplet size differences observed after in vitro digestion of pasteurized cream (22) influences the intestinal absorption of lipids. Therefore, conducting a study on a bigger group of people, standardizing diets prior the trial, ensuring subject homogeneity, etc. could help to limit variability and remove some of the sources of possible uncertainties that could influence the results.

Regarding measures of protein digestion and metabolism, results were not conclusive due to the limited number of studies available, and the variation in outcome measures used. Yet, both studies reported findings on both sexes, of similar ages $(\sim 20$ 30 years), and consuming similar quantities (400 vs. $500 \mathrm{~mL}$ ). The study with a high risk of bias, non-commercial heating methods, and shorter follow-up (2 h) (18) reported a significant loss in the plasma lysine concentration with milk heated for a longer period of time, but those results did not match a more recent study with a better quality assessment, standard processing (i.e., PM and UHT) and longer follow-up (8h) (17) that reported no significant changes in the serum AAs or in the lysine serum concentration with UHT milk relative to MF or PM. The latter study also provided a separated analysis of dispensable (non-essential) AAs, indispensable (essential) AAs and lysine concentration in the serum, although, no further information about the AA composition in serum was provided. Further, the heat treatment of the milks between studies differed: oven heated at $66^{\circ} \mathrm{C}$ for $1-5 \mathrm{~h}$ [lower temperature and longer duration than standard processing methods $(32,44)]$ vs. UHT, pasteurized and homogenized milk. These differences limit the ability to compile the effects of any one type of heat treatment on AA appearance, and in terms of relevance to commonly consumed products, data were available from only a single study.
This review highlights the current lack of studies investigating the impacts of milk heat treatment on protein and lipid digestion involving human adult participants. In vitro studies have been able to demonstrate that processing affects milk structure and thus digestion by changing the rates of protein hydrolysis and the release of milk fat $(5-7,32)$ but this is not yet the case for in vivo studies on humans. Variability in methodologies used further complicates the ability to draw consensus conclusions across the studies that were identified. Across studies, the milks underwent various heat treatment methods, with few comparable comparisons between the studies. One study compared UHT milk and pasteurized and homogenized milk with pasteurized milk only (16); no non-heated milk was used as a control. Three other studies used non-heated milk as a control; however, different processing techniques were still used. One study used raw milk (as NM) (15), another microfiltered milk (17) and one study used lactose hydrolyzed freeze-dried skim milk (18). Indeed, not having the same control makes it more difficult to compare findings and provide confident summaries. Likewise, the methods used to assess study outcomes, particularly protein and amino acid kinetics, were diverse. Only one study measured dietary $\mathrm{N}$ transfer and showed that UHT processing reduced this outcome compared to pasteurization and microfiltration (17). While this suggests heat treatment may have implications for long-term health outcomes relative to protein utilization, none of the other studies included in this review assessed this outcome so further investigation is required to clarify the impact that the different heat treatments have on the use and retention of ingested milk proteins.

This review has a number of strengths. The objective of the study was developed based on an established methodology (PICOT) and the search is well-described and rigorous, including a large amount of words and terms relevant for the objective. In addition, two of the authors did individual screening of the search results. A quality assessment was performed using the Cochrane risk-of-bias assessment tool for randomized trials, to provide an indication of the quality of research on which any conclusions were based. Finally, we have undertaken a critical discussion of the findings.

We acknowledge several limitations of the review. First and foremost, very few relevant studies were found, and the number of study subjects was relatively small, making it difficult to draw any clear conclusions. However, we believe this is in itself interesting, as it demonstrates that relatively little research has addressed the posed question, and this therefore clearly indicates that further research is required. It is also possible that content available in the gray literature may have proven useful, although given the nature of this rapid review a conscious decision was made to exclude such literature.

Because of the small number of studies identified, and the range of different heat treatment regimes used in these studies, it was also not possible to make a meaningful comparison of particular heat treatments, and we also note this as a limitation.

Although we believe this was an extensive search, some key words that could be considered relevant were not included, for example "apoB-48" and "chylomicrons" which are relevant to lipid digestion. However, we note that a 
subsequent search including these terms did not identify any additional studies.

\section{CONCLUSION}

The present review showed an overall shortage of studies conducted on this topic on adult human subjects; as such, no solid conclusions about the impact of heat treatment of milk on protein and lipid digestion can be made. Differences between types of milk heat treatment could be shown on plasma fatty acid composition by the different articles but limitations to those findings prevented any conclusion about the way lipids and fatty acids are metabolized. No conclusive results could be obtained about how heat treatment affects postprandial protein metabolism. The lack of conclusive findings regarding both lipid and protein metabolism also makes it difficult to draw conclusions regarding long-term health impacts of consuming milks undergoing different heat treatments, although there may be implications on long-term protein utilization. Therefore, the main finding from this work is that further investigation is required to link the effects of heat treatment observed in vitro to in vivo observations, and to understand the relevance to human health.

\section{DATA AVAILABILITY STATEMENT}

The original contributions presented in the study are included in the article/Supplementary Material, further inquiries can be directed to the corresponding author.

\section{REFERENCES}

1. Bigouette JP, Bethel JW, Bovbjerg ML, Waite-Cusic JG, Häse CC, Poulsen KP. Knowledge, attitudes and practices regarding raw milk consumption in the pacific northwest. Food Prot Trends. (2018) 38:104-10.

2. Claeys WL, Cardoen S, Daube G, De Block J, Dewettinck K, Dierick K, et al. Raw or heated cow milk consumption: review of risks and benefits. Food Control. (2013) 31:251-62. doi: 10.1016/j.foodcont.2012.09.035

3. EFSA BIOHAZ Panel (EFSA Panel on Biological Hazards) 2015. Scientific opinion on the public health risks related to the consumption of raw drinking milk. EFSA J. (2015) 13:3940. doi: 10.2903/j.efsa.2015.3940

4. International Dairy Federation. Heat Treatment of Milk - Overview, IDF Factsheet 001/2018-02. Brussels: International Dairy Federation (2018).

5. Tunick MH, Ren DX, Van Hekken DL, Bonnaillie L, Paul M, Kwoczak R, et al. Effect of heat and homogenization on in vitro digestion of milk. J Dairy Sci. (2016) 99:4124-39. doi: 10.3168/jds.2015-10474

6. Ye A, Liu W, Cui J, Kong X, Roy D, Kong Y, et al. Coagulation behaviour of milk under gastric digestion: effect of pasteurization and ultra-high temperature treatment. Food Chem. (2019) 286:216-25. doi: 10.1016/j.foodchem.2019.02.010

7. Ye A, Cui J, Dalgleish D, Singh H. Effect of homogenization and heat treatment on the behavior of protein and fat globules during gastric digestion of milk. J Dairy Sci. (2017) 100:36-47. doi: 10.3168/jds.2016-11764

8. Hansen SF, Petrat-Melin B, Rasmussen JT, Larsen LB, Ostenfeld MS, Wiking L. Placing pasteurisation before or after microfiltration impacts the protein composition of milk fat globule membrane material. Int Dairy J. (2018) 81:35-41. doi: 10.1016/j.idairyj.2017.12.015

9. Lacroix M, Leonil J, Bos C, Henry G, Airinei G, Fauquant J, et al. Heat markers and quality indexes of industrially heat-treated [15N] milk protein measured in rats. J Agric Food Chem. (2006) 54:1508-17. doi: 10.1021/jf051304d

\section{AUTHOR CONTRIBUTIONS}

MF designed and conducted the research, analyzed data, and wrote the paper. MPGB wrote the paper. NG conducted the research and wrote the paper. AMM designed and conducted research, analyzed data, and wrote the paper and had primary responsibility for final content. All authors contributed to the article and approved the submitted version.

\section{FUNDING}

Salary support was funded by the New Zealand Ministry of Business Innovation and Employment (MBIE) through the New Zealand Milks Mean More Programme (MAUX1803). MBIE had no role in the design or analysis of the study, or in the writing of this article.

\section{ACKNOWLEDGMENTS}

We thank the Liggins Institute, University of Auckland for supporting MF to complete this work. Thanks to Dr Simon Love day and Dr Carlos Montoya (AgResearch Limited) for critical review of the manuscript.

\section{SUPPLEMENTARY MATERIAL}

The Supplementary Material for this article can be found online at: https://www.frontiersin.org/articles/10.3389/fnut.2021. 643350/full\#supplementary-material

10. Guyomarc'h F, Warin F, Donald Muir D, Leaver J. Lactosylation of milk proteins during the manufacture and storage of skim milk powders. Int Dairy J. (2000) 10:863-72. doi: 10.1016/S0958-6946(01)00020-6

11. Featherstone RM, Dryden DM, Foisy M, Guise JM, Mitchell MD, Paynter $\mathrm{RA}$, et al. Advancing knowledge of rapid reviews: an analysis of results, conclusions and recommendations from published review articles examining rapid reviews. Syst Rev. (2015) 4:1-8. doi: 10.1186/s13643-015-0040-4

12. Tricco AC, Antony J, Zarin W, Strifler L, Ghassemi M, Ivory J, et al. A scoping review of rapid review methods. BMC Med. (2015) 13:224. doi: 10.1186/s12916-015-0465-6

13. Higgins J, Thomas J, Chandler J, Cumpston M, Li T, Page M, et al. Cochrane Handbook for Systematic Reviews of Interventions. 2nd ed. Chichester, UK: John Wiley \& Sons (2019).

14. Higgins JPT, Sterne JAC, Savović J, Page MJ, Hróbjartsson A, Boutron I, et al. A revised tool for assessing risk of bias in randomized trials. Cochrane Database Syst Rev. (2016) 10(Suppl 1):29-31.

15. Nuora A, Tupasela T, Tahvonen R, Rokka S, Marnila P, Viitanen M, et al. Effect of homogenised and pasteurised versus native cows' milk on gastrointestinal symptoms, intestinal pressure and postprandial lipid metabolism. Int Dairy J. (2018) 79:15-23. doi: 10.1016/j.idairyj.2017.11.011

16. Nuora A, Tupasela T, Jokioja J, Tahvonen R, Kallio H, Yang B, et al. The effect of heat treatments and homogenisation of cows' milk on gastrointestinal symptoms, inflammation markers and postprandial lipid metabolism. Int Dairy J. (2018) 85:184-90. doi: 10.1016/j.idairyj.2018.05.017

17. Lacroix M, Bon C, Bos C, Léonil J, Benamouzig R, Luengo C, et al. Ultra high temperature treatment, but not pasteurization, affects the postprandial kinetics of milk proteins in humans. J Nutr. (2008) 138:23427. doi: 10.3945/jn.108.096990

18. Ljungqvist BG, Blomstrand E, Hellstrom A, Lindell I, Olsson ME, Svanberg US. Plasma amino acid response to single test meals in humans. 
VI. Determination of available lysine. Res Exp Med. (1979) 174:20919. doi: 10.1007/BF01851413

19. McCarthy KS, Parker M, Ameerally A, Drake SL, Drake MA. Drivers of choice for fluid milk versus plant-based alternatives: what are consumer perceptions of fluid milk? J Dairy Sci. (2017) 100:6125-38. doi: 10.3168/jds.2016-12519

20. Jin S, Yuan R, Zhang Y, Jin X. Chinese consumers' preferences for attributes of fresh milk: a best-worst approach. Int J Environ Res Public Health. (2019) 16:4286. doi: $10.3390 /$ ijerph16214286

21. Rérat A, Calmes R, Vaissade P, Finot P-A. Nutritional and metabolic consequences of the early maillard reaction of heat treated milk in the pig. Significance for man. Eur J Nutr. (2002) 41:1-11. doi: 10.1007/s003940200000

22. Gallier S, Cui J, Olson TD, Rutherfurd SM, Ye A, Moughan PJ, et al. In vivo digestion of bovine milk fat globules: effect of processing and interfacial structural changes. I. Gastric digestion. Food Chem. (2013) 141:327381. doi: 10.1016/j.foodchem.2013.06.020

23. Boehm G, Räihä NCR. Heat treatment of infant formula: effect on postprandial serum $\alpha$-amino-nitrogen concentrations in verylow-birth-weight infants. J Pediatr Gastroenterol Nutr. (1994) 18:371-4. doi: 10.1097/00005176-199404000-00020

24. de Oliveira SC, Bellanger A, Ménard O, Pladys P, Le Gouar Y, Dirson E, et al. Impact of human milk pasteurization on gastric digestion in preterm infants: a randomized controlled trial. Am J Clin Nutr. (2017) 105:37990. doi: 10.3945/ajcn.116.142539

25. Perrella SL, Hepworth AR, Gridneva Z, Simmer KN, Hartmann PE, Geddes DT. Gastric emptying and curding of pasteurized donor human milk and mother's own milk in preterm infants. J Pediatr Gastroenterol Nutr. (2015) 61:125-9. doi: 10.1097/MPG.0000000000000776

26. Géczi G, Horváth M, Kaszab T, Alemany GG. No major differences found between the effects of microwave-based and conventional heat treatment methods on two different liquid foods. PLoS ONE. (2013) 8:e53720. doi: 10.1371/journal.pone.0053720

27. Kelleher CM, O'Mahony JA, Kelly AL, O'Callaghan DJ, Kilcawley KN, McCarthy NA. The effect of direct and indirect heat treatment on the attributes of whey protein beverages. Int Dairy J. (2018) 85:14452. doi: 10.1016/j.idairyj.2018.05.011

28. Kelleher CM, Aydogdu T, Murphy KM, O'Mahony JA, Kelly AL, O'Callaghan DJ, et al. The effect of protein profile and preheating on denaturation of whey proteins and development of viscosity in milk protein beverages during heat treatment. Int J Dairy Technol. (2020) 73:494501. doi: 10.1111/1471-0307.12679

29. Bernat N, Cháfer M, Rodríguez-García J, Chiralt A, González-Martínez C. Effect of high pressure homogenisation and heat treatment on physical properties and stability of almond and hazelnut milks. LWT Food Sci Technol. (2015) 62:488-96. doi: 10.1016/j.lwt.2014.10.045

30. Kaur J, Katopo L, Ashton J, Whitson A, Kasapis S. Molecular interactions of milk protein with phenolic components in oat-based liquid formulations following UHT treatment and prolonged storage. J Sci Food Agric. (2018) 98:1794-802. doi: 10.1002/jsfa.8655

31. Talsma EFF, Moretti D, Ly SCC, Dekkers R, van den Heuvel EGHMG, Fitri A, et al. Zinc absorption from milk is affected by dilution but not by thermal processing, and milk enhances absorption of Zinc from high-phytate rice in young dutch women. J Nutr. (2017) 147:1086-93. doi: 10.3945/jn.116.244426

32. van Lieshout GAA, Lambers TT, Bragt MCE, Hettinga KA. How processing may affect milk protein digestion and overall physiological outcomes: a systematic review. Crit Rev Food Sci Nutr. (2020) 60:2422-45. doi: 10.1080/10408398.2019.1646703
33. Prodhan UK, Shrestha A, Karlström HJ, Martinsson JA, Nilsson NJ, Barnett MPG, et al. Do lactose intolerant individuals efficiently absorb protein from acute milk consumption? Proceedings. (2019) 8:39. doi: 10.3390/proceedings 20190 08039

34. Ghimeray PS, Shrestha A, Karlström J, Martinson J, Nilsson J, Barnett $\mathrm{M}$, et al. Riboflavin bioavailability varies with milk type and is altered in self-reported dairy intolerance states (P24-012-19). Curr Dev Nutr. (2019) 3:nzz044-P24. doi: 10.1093/cdn/nzz044.P24012-19

35. Le Feunteun S, Barbé F, Rémond D, Ménard O, Le Gouar Y, Dupont D, et al. Impact of the dairy matrix structure on milk protein digestion kinetics: mechanistic modelling based on mini-pig in vivo data. Food Bioprocess Technol. (2014) 7:1099-113. doi: 10.1007/s11947-013-1116-6

36. Nyakayiru J, Van Lieshout GAA, Trommelen J, Van Kranenburg J, Verdijk LB, Bragt MCE, et al. The glycation level of milk protein strongly modulates post prandial plasma lysine availability in vivo in humans. Br J Nutr. (2020) 123:545-52. doi: 10.1017/S0007114519002927

37. Antes G. The new CONSORT statement. BMJ. (2010) 340:666. doi: 10.1136/bmj.c1432

38. Keller J, Layer P. The pathophysiology of malabsorption. Viszeralmedizin. (2014) 30:7. doi: 10.1159/000364794

39. Bowie MD. Effect of lactose-induced diarrhoea on absorption of nitrogen and fat. Arch Dis Child. (1975) 50:363-6. doi: 10.1136/adc.50.5.363

40. Dallas DC, Sanctuary MR, Qu Y, Khajavi SH, Van Zandt AE, Dyandra M, et al. Personalizing protein nourishment. Crit Rev Food Sci Nutr. (2017) 57:3313-31. doi: 10.1080/10408398.2015.1117412

41. Vidal-Lletjós S, Beaumont M, Tomé D, Benamouzig R, Blachier F, Lan A. Dietary protein and amino acid supplementation in inflammatory bowel disease course: what impact on the colonic mucosa? Nutrients. (2017) 9:310. doi: 10.3390/nu9030310

42. Barton SH, Kelly DG, Murray JA. Nutritional deficiencies in celiac disease. Gastroenterol Clin North Am. (2007) 36:93-108. doi: 10.1016/j.gtc.2007. 01.006

43. Sadik R, Stotzer P -o., Simrén M, Abrahamsson H. Gastrointestinal transit abnormalities are frequently detected in patients with unexplained GI symptoms at a tertiary centre. Neurogastroenterol Motil. (2007) 20:197205. doi: 10.1111/j.1365-2982.2007.01025.x

44. Codex Alimentarius. Code of Hygienic Practice for Milk and Milk Products. Rome: World Health Organization (WHO) and the Food and Agriculture Organization of the United Nations (FAO) (2004).

Conflict of Interest: MPGB and AMM are current employees of AgResearch Limited.

The remaining authors declare that the research was conducted in the absence of any commercial or financial relationships that could be construed as a potential conflict of interest.

Copyright (c) 2021 Fatih, Barnett, Gillies and Milan. This is an open-access article distributed under the terms of the Creative Commons Attribution License (CC BY). The use, distribution or reproduction in other forums is permitted, provided the original author(s) and the copyright owner(s) are credited and that the original publication in this journal is cited, in accordance with accepted academic practice. No use, distribution or reproduction is permitted which does not comply with these terms. 